
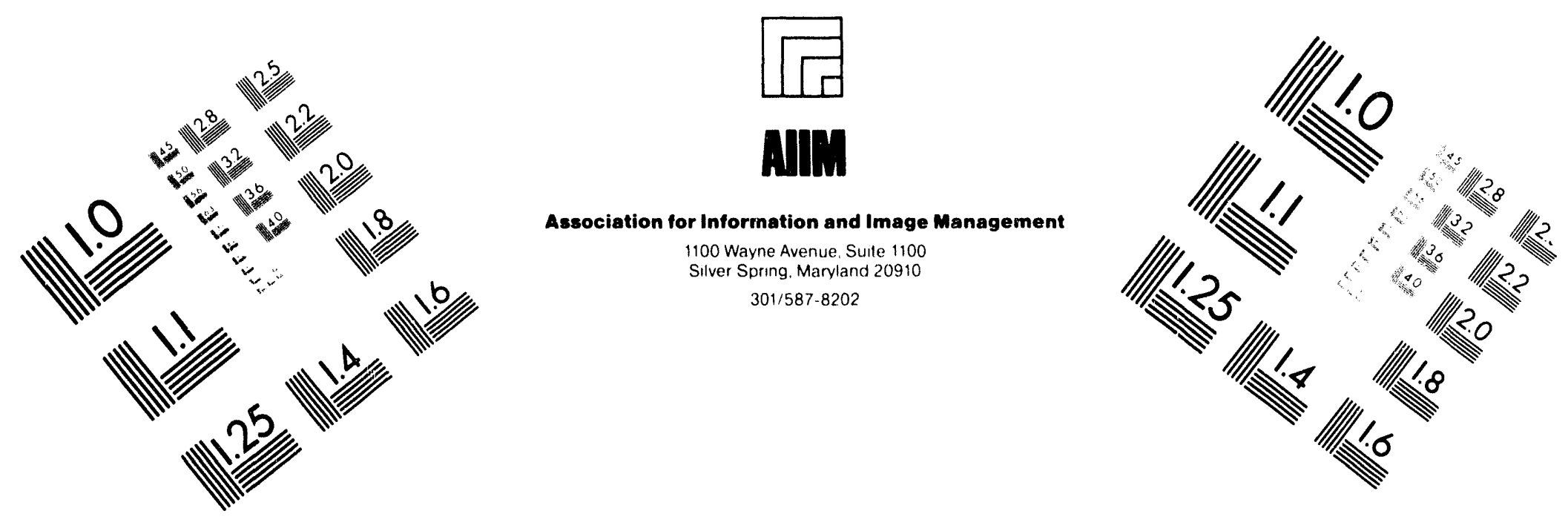

\title{
Centimeter
}

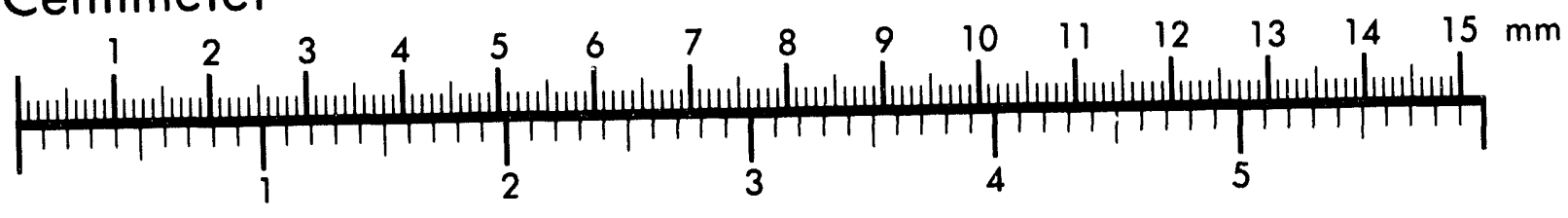
Inches
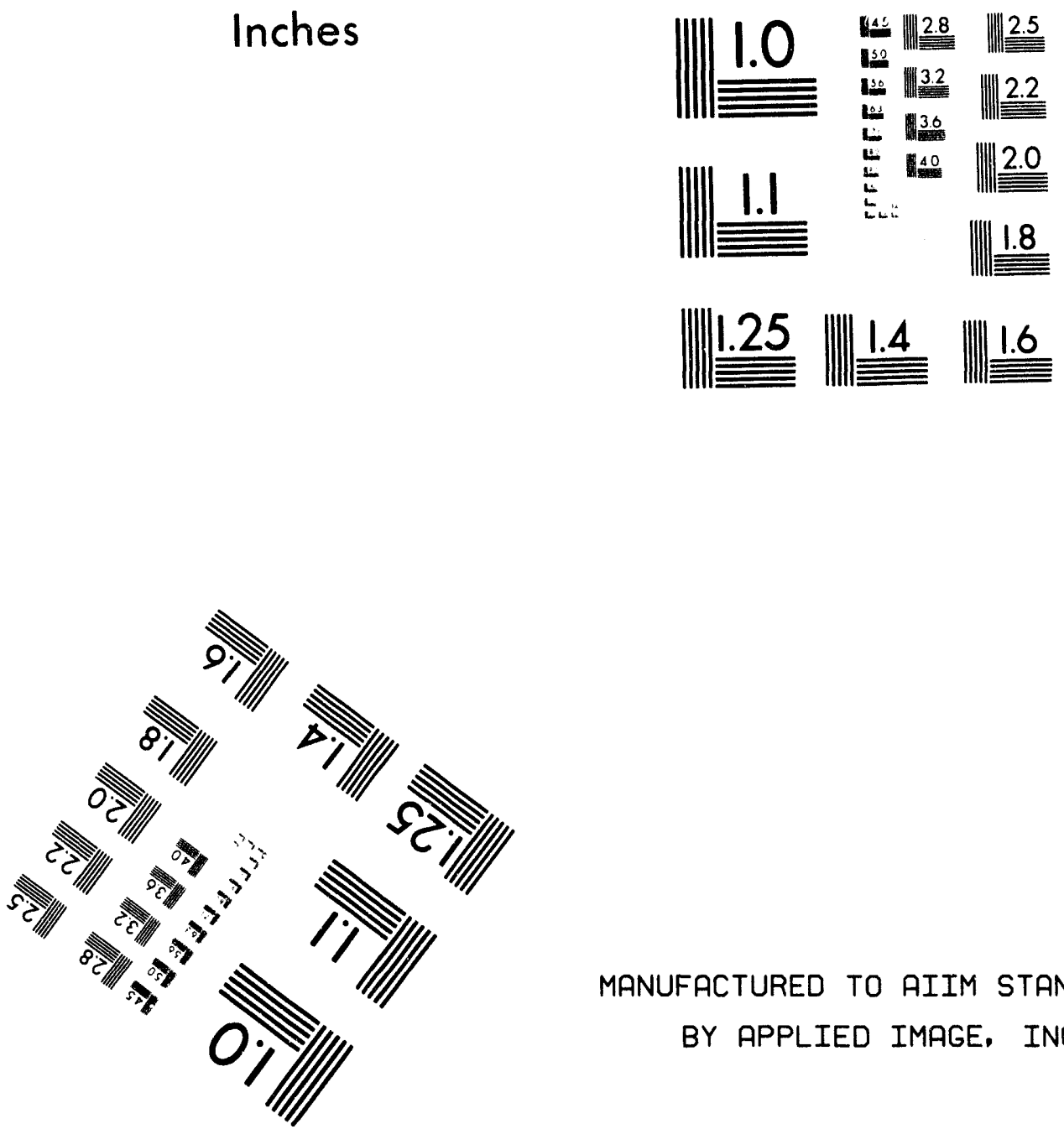

MANUFACTURED TO AIIM STANDARDS

BY APPLIED IMAGE, INC.

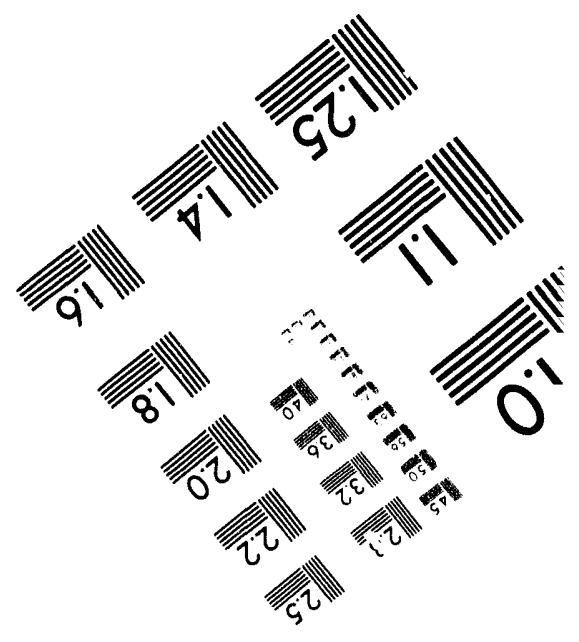



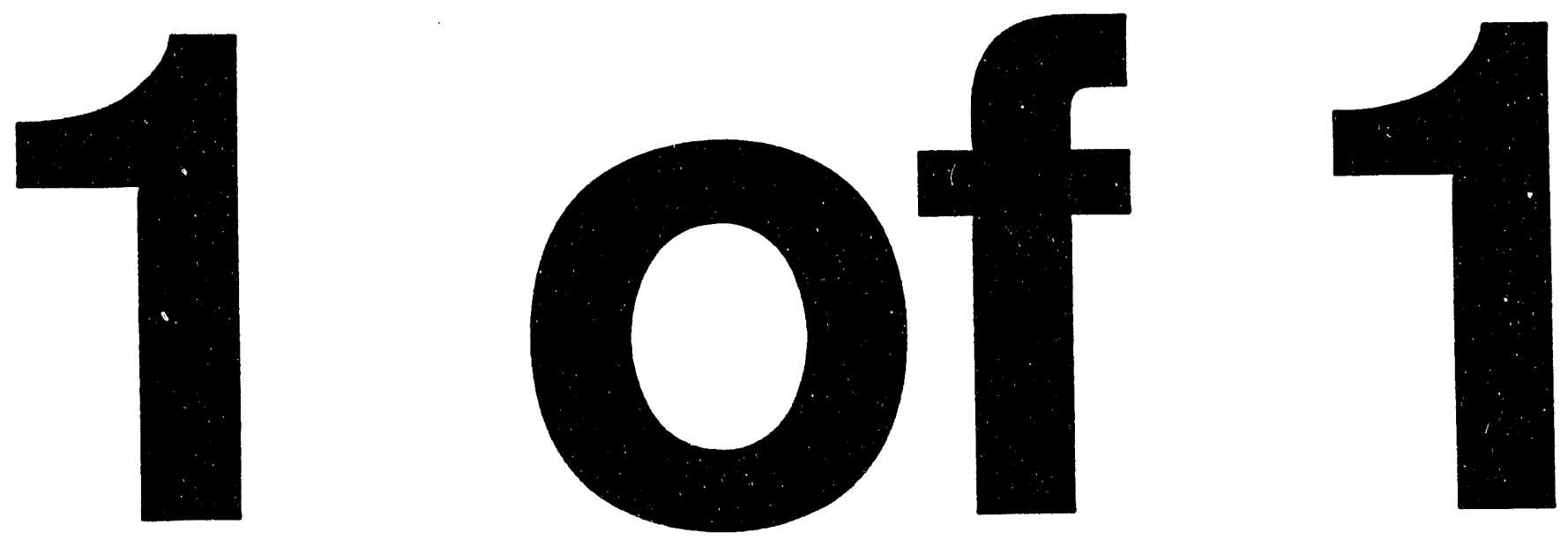
KCP.613-5482

Distribution Category UC-706

Approved for public release; distribution is unlimited.

\section{DEVELOPMENT OF HIGH RELIABILITY PLANAR CHIP INDUCTORS}

H. W. Swanson, Jr.

Published August 1994

Paper submitted to Electrical Manufacturing and Coil Winding Conference September 27, 1994

Chicago, IL 


\title{
DEVELOPMENT OF HIGH RELIABILITY PLANAR CHIP INDUCTORS
}

\author{
Harold W. Swanson, Jr. \\ AlliedSignal, Inc.* \\ Kansas City Division
}

\section{Abstract}

A process for fabrication of multilayer planar chip inductors on ceramic wafers has been developed. This paper will summarize the progress made in the use of step-and-repeat print processes to fabricate a family of high reliability planar chip inductors for surface mount RF applications. Experimental data on thick-film gold and plated-copper windings are presented. In addition, the development of an automated RF probe station and waferized calibration standards are discussed.

\section{Introduction}

This project was initiated to reduce cost and flow time of component qualification and procurement for a family of MIL-SPEC-M83446/8 type (2.794 X $2.667 \times 1.778 \mathrm{~mm}$ ) surface mount chip inductors for weapons programs. The project was funded by the Department of Energy [1] and sponsored by the Sandia/New Mexico National Laboratories.

An industry search for high-reliability chip inductors in the $10-500 \mathrm{nH}$ range having $\pm 5 \%$ tolerances revealed that suppliers rely on semiautomated processes, operator skills, and lot screening to meet customer requirements. While component engineers have applied process characterization, design of experiments, and statistical process controls to improve yields and process capability index (Cpk) to meet these requirements, system designers are now specifying $\pm 2 \%$ components to minimize costly tuning of RF assemblies.

Current technology for the fabrication of surface mount chip inductors has changed little in the past several decades. Typically, magnet wire is wound on a phenolic or powdered iron bobbin. The wound bobbin is attached to a lead frame, and the magnet wire is soldered or welded to the lead frame. The discrete parts are then transfer molded to the final mechanical configuration and electrically tested to customer requirements. Manufacturers have, in some cases, automated the critical winding and lead attachment processes, but variations in magnet wire distribution, bobbin geometry, and assembly processes result in typical inductance tolerances of $\pm 10 \%$ at $90 \%$ yield factors. Requirement for $\pm 5 \%$ or better parts require in-process screening and final acceptance testing which all adversely impact unit cost and flow time. In addition to the extensive qualification tests necessary to qualify a family of chip inductors, lot sample destructive physical analysis and environmental tests are required to verify material compatibility and product reliability.

Historically, the reliability of inductive devices, when compared to other discrete passive and active components, has lagged behind. While the materials and manufacturing processes for other devices have gone from individual to controlled batch processing, fabrication methods and materials for magnetic devices have, for the most part, remained unchanged. As shown in FIGURE 1, the ratio of inductor part failure to population for a typical mili-

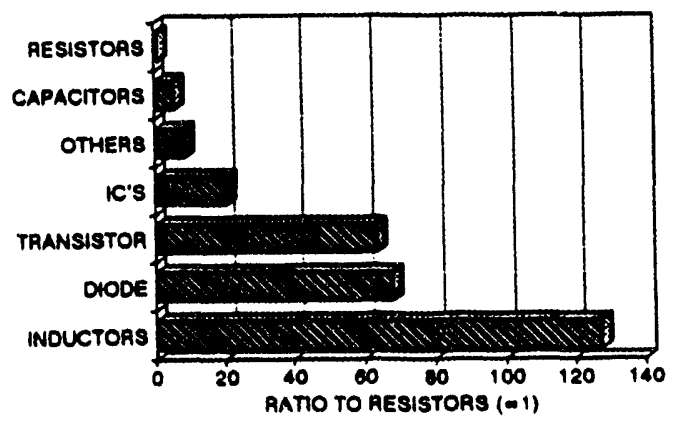

FIGURE 1

Ratio of Part Failure to Population for Military Equipment

tary system is more than 100 times higher than the ratio of resistor failures. This data [2], gathered over several years at a major aerospace company's receiving inspection, is for all magnetic devices, not specifically chip inductors, and is shown to indicate a need for improvement.

${ }^{\star}$ Operated for the United States Department of Energy under Contract No. DE-ACO4-76-DP00613.

- Copyright AlliedSignal Inc., 1993 


\section{Statement of Task}

The stated goal of this project was to develop a family of planar chip inductors meeting all of the requirements of MIL-SPEC-M83446/8 with a Cpk of $\geq 1.67$ on $\pm 5 \%$ inductors over the range of $5-100 \mathrm{nH}$. This range of chip inductors represents approximately $90 \%$ of all chip inductors used on current RF assemblies. In addition, the devices must be qualified to withstand $240^{\circ} \mathrm{C}$ processing, $125^{\circ} \mathrm{C}$ to $-55^{\circ} \mathrm{C}$ operating temperatures, and meet MIL-STD-883D, method 2007.2 and method 2002.3, test condition B (shock and vibration requirements).

\section{Design Concept}

In an attempt to reduce the unit-to-unit process variations and to automate the process, the initial design utilized thick-film gold multi-layer screen print processes on a ceramic platform. The coil winding was a spiral planar design as shown in FIGURE 2. There were two turns per layer with via interconnects, fired ceramic interlayer insulation, gold-plated thru holes, and metalized pads for surface mount application on thick- or thin-film networks: The advantages of using the thick-film gold on ceramic include:

- Coefficient of thermal expansion (COTE) match for chip inductors and TKN or TFN next assemblies.

- All thick-film processes $\geq 700^{\circ} \mathrm{C}$, next assembly processing temperature is $240^{\circ} \mathrm{C}$ maximum.

- Improved Cpk values resulting from repeatable multilayer processes.

- Gold-plated pads with nickel barrier for either $\mathrm{Sn}-\mathrm{Pb}$ or $\mathrm{Pb}-\mathrm{In}$ solder plate.

\section{Thick-Film Gold Wafer Evaluation}

The initial wafer configuration is shown in FIGURE 3. The 1.27 thick $\times 19.0 \mathrm{Em}$ diameter wafer was sliced from an Iso-press formed green ceramic log. Thru hoies, slots between and around individual chips, and locating flats were machined in the green ceramic wafer prior to firing to reduce machining after firing. The prototype wafers were fabricated with one turn per laver, 20.3 um thick X $254 \mu \mathrm{m}$

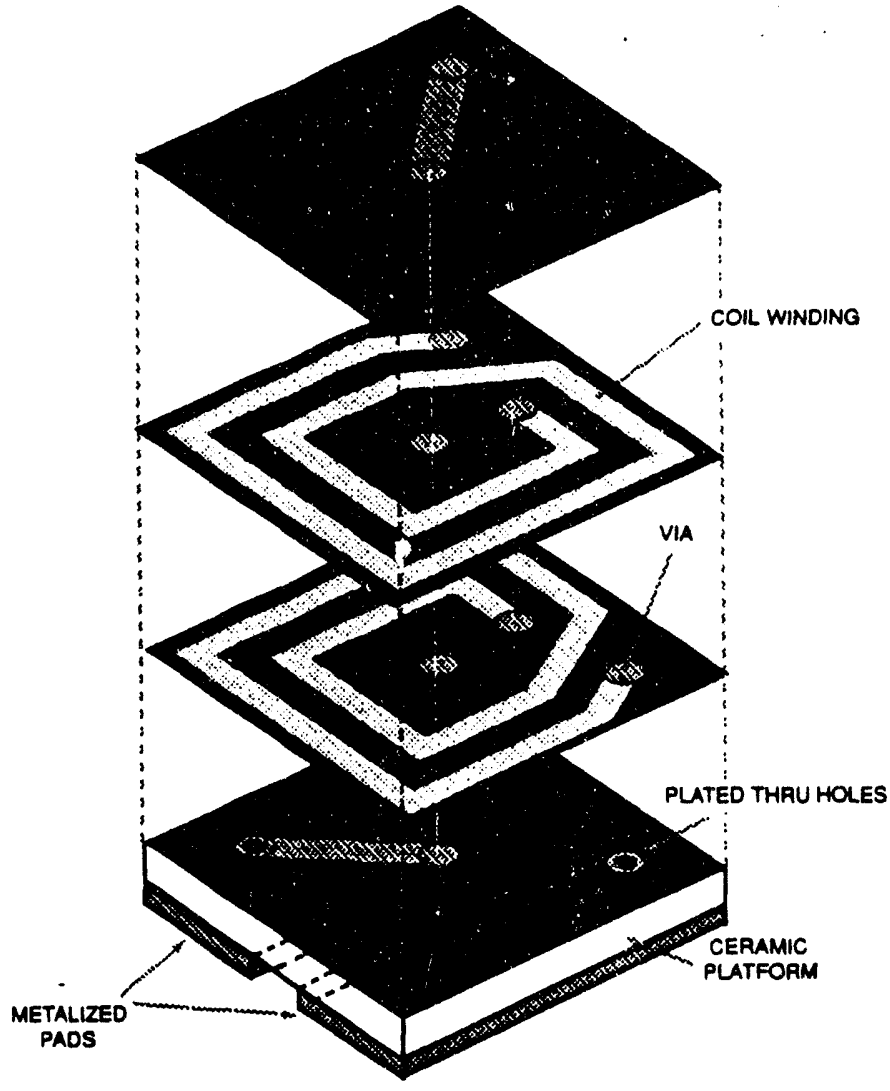

FIGURE 2

Coil Winding Assembly

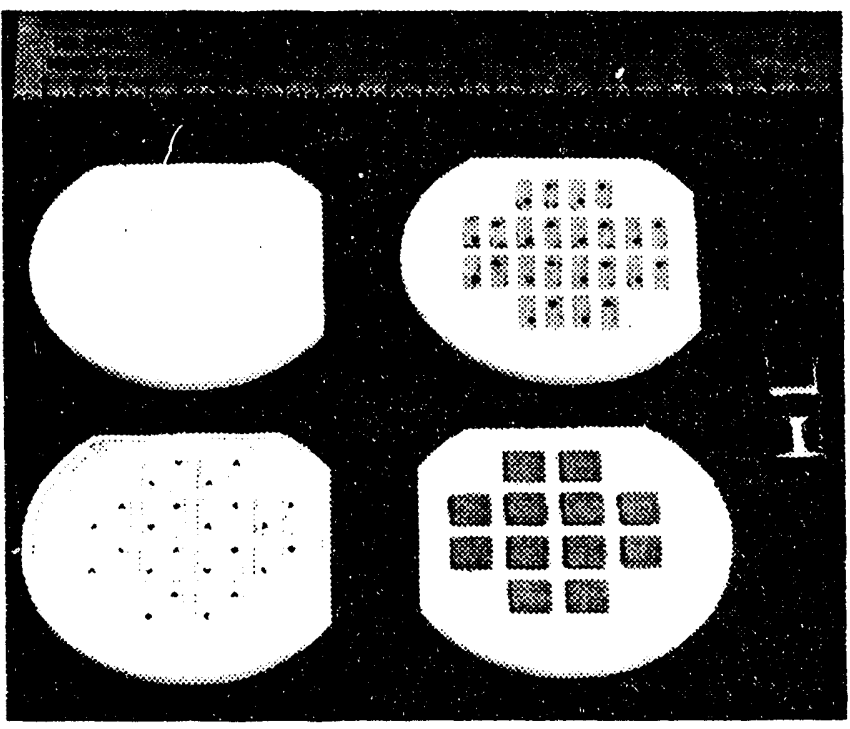

FIGURE 3

Chip Inductor Wafer Assembly 
wide, thick-film gold conductors and $25.4 \mu \mathrm{m}$ interlayer insulation.

FIGURE 3 shows the wafer at various stages of processing. Clockwise from the top left are the fired ceramic blank, backside metalization, topside windings with cover coat, and the solder-plated backside. The prototype wafers had twelve parts per wafer and were built with two, four and six turns per device. The results of the prototype build are listed in TABLE 1.

\begin{tabular}{|c|c|c|c|c|c|}
\hline TURNS & FREO $\left(M H_{2}\right)$ & $L(\mathrm{nH})$ & Cok $\bigcirc \%$ & $\begin{array}{c}0 \\
\circ \text { (MIN LIMIT) }\end{array}$ & \begin{tabular}{|c|} 
SRF $(g \mathrm{~Hz})$ \\
L(MIN LIMIT) \\
\end{tabular} \\
\hline \multirow{2}{*}{2} & 100 & 18.14 & 1.05 & $\begin{array}{l}17 \\
\cdot(50)\end{array}$ & $\mid 0.65^{\circ}(>1.0)$ \\
\hline & 150 & 18.22 & 1.04 & 24 & \\
\hline \multirow{2}{*}{4} & 100 & 56.4 & 1.9 &.$^{24}(47)$ & $0.52 \cdot(0.85)$ \\
\hline & 150 & 56.6 & 1.8 & 32 & \\
\hline \multirow{3}{*}{6} & 100 & 117.2 & 1.0 & 26 & \\
\hline & & & & $\cdot(47)$ & $0.27 \quad(0.24)$ \\
\hline & 150 & 129 & 0.95 & 33 & \\
\hline
\end{tabular}

NOTE:

(*) Minimum Specification Requirement

TABLE 1

Electrical Characteristics of Thick Film Gold Wafers

Although derr.unstrating design feasibility, the prototype wafers still had some serious shortcomings when compared to similar wire wound devices. On the positive side were the Cpk and yield values. The pre-screen Cpk on current wire wound product is in the area of 0.6 while the overall yields for $\pm 5 \%$ product is approximately $70 \%$. The Cpk for the ten wafers from this prototype build was $>1.0$ and the yield approximately $90 \%$. The downside of this design was in the $Q$ factor and SRF. $Q$, the ratio of $\boldsymbol{\omega} \cup \mathrm{R}$, was adversely affected by the high DCR of the winding and the skin effect $(\partial)$ of thick-film gold $(5.0 \mu \mathrm{m}$ at $150 \mathrm{MHz})$, the ratio of conductor thickness $(t)$ to width $(w)$, and the $\partial / t$ ratio [3]. The low SRF values were caused by the large interlayer capacitance between the parallel conductive layers. One disadvantage of this process was the iso-press limit of $2.54 \mathrm{~cm}$ diameter, which restricts the number of parts per wafer. Also, the firing cycle per level of two to three hours for the winding and insulation increases product flow time.

The prototype design did demonstrate that it was feasible to use multilayer step-and-repeat screen printing processes to fabricate planar chip inductors on a ceramic wafer platform, but it was obvious that a new approach was necessary to make the planar design a viable alternate for current magnet wire wound devices.

\section{Plated Copper Wafer Evaluation}

The next phase of the project was to improve the $Q$ factor and SRF. Double screen printing of gold or silver was not practical to reduce DCR and the $t / w$ ratio, so a change in material and process was required. Remtec, Inc., a company specializing in the design and fabrication of low cost, high power multilayer copper-on-ceramic substrates for power and RF electronics, was contacted to determine if their patented plating process would be applicable for RF microelectronics applications. The process included the firing of a silver-copper seed layer on the ceramic platform to provide a base for the plated copper conductors. A coating of an enhanced polyimide material provides the interlayer insulation for the windings. The second and subsequent conductive layers have a copper filled epoxy as the seed layer for the plated copper winding. The advantage of this system was that the OFHC copper winding with a $50 \times 250 \mu \mathrm{m}$ cross section would reduce the DCR of the winding thus improving the $Q$ factor. In addition, the process time per layer was reduced from three hours to one hour. The primary disadvantage of the plated copper/polyimide system was the processing temperatures, and thus the maximum temperature rating of the system, which went from $700^{\circ} \mathrm{C}$ for the fired ceramic to $260^{\circ} \mathrm{C}$ for the plated copper design. There were other positive factors in the decision to go to plated copper configuration. These include:

Thicker interlayer insulation to reduce winding capacitance and improve SRF characteristics.

- Larger winding cross section to permit higher current capacity ( $>2 A)$ for RF filter and power applications.

- Design easily expandable to larger wafer size to permit hundreds rather than twelve devices per wafer.

The entire manufacturing process can be automated from screen printing through wafer dicing. 
Copper filled thru holes to isolate top side windings from flux and solvent entrapment during next assembly processing.

Multiple turns per layer to reduce the number of winding levels.

Fractional turns to trim inductor to specific value.

To evaluate the copper-plated/polyimide process, wafers having 2 thru 8 turns were fabricated on the $19 \mathrm{~mm}$ diameter ceramic platform. The results are listed in TABLE 2.

\begin{tabular}{|c|c|c|c|c|c|}
\hline TURS & FAEO (MHZ) & $L(\mathrm{NH})$ & Cok $\bigcirc 5 \%$ & 0 & SAF $(\mathrm{OH} Z \mathrm{H}$ \\
\hline \multirow{3}{*}{2} & 100 & 8.92 & 1.16 & 40 & \multirow{3}{*}{$>1.0$} \\
\hline & & & & & \\
\hline & 150 & 8.92 & 1.32 & 43 & \\
\hline \multirow{3}{*}{4} & 100 & 26.9 & 0.65 & 28 & \multirow{3}{*}{0.81} \\
\hline & & & & & \\
\hline & 150 & 27.4 & 0.65 & 38 & \\
\hline \multirow{3}{*}{6} & 50 & 55.2 & 1.16 & 22 & \multirow{3}{*}{0.53} \\
\hline & & & & & \\
\hline & 100 & 54 & 1.01 & 28 & \\
\hline \multirow{3}{*}{8} & 25 & 89.3 & 1.02 & 16 & \multirow{3}{*}{0.43} \\
\hline & & & & & \\
\hline & 50 & 89 & 0.94 & 22.5 & \\
\hline
\end{tabular}

NOTE:

Conductors - $25.4 \times 254 \mu \mathrm{m}$, two turns per level Insulator $-37.6 \mu \mathrm{m}$

TABLE 2

Electrical Characteristics of Plated Copper Wafers

The $Q$ and SRF improved over the thick-film winding design; however, the self inductance per turn for two turns per layer was approximately $1 / 2$ that of the one turn per layer thick-film gold devices. This reduction of inductance per turn can be explained by examining the approximation for self inductance of a single turn per layer to that of multiple turns per layer for an air core device [4]. For a single turn, an approximation for the self inductance of a square conductor with dimension of $2 \mathrm{a}$ on a side, and conductor width $w$ is given by

$$
L_{1}=\left[\left(4 \mu_{0} a\right) / \pi\right] \ln (4 a / w)
$$

where $\mu_{0}$ is the permeability of air; a and $w$ are in $\mathrm{cm}$. For multiple-turn planar inductors with concentric conductors connected in series, the expression has been empirically modified to reduce errors and compensate for small $4 a_{i} / w$ terms for the inner turns and is given by

$$
L_{a i}=\left[\left(4 \mu_{0} a_{i}\right) / \pi\right] \ln \left[\left(4 a_{i} / w\right)-1\right]
$$

where the total inductince per layer is equal to the sum of self inductance of each turn on that layer. Multilayer values of self inductance for planar chip inductors having small $4 a_{j} / w$ ratios $(5$ to 10$)$ can best be determined empirically because of imperfect coupling between layers, the distributed capacitance, and mutual inductance factors at the RF test frequencies that are not considered in the general equation.

\section{Large Size Wafer Evaluation}

As stated earlier, one of the advantages of using the plated copper-on-ceramic design was the fact that the ceramic platform could easily be expanded to a large wafer. The platform selected for this evaluation was a company standard Herman $114.3 \mathrm{X}$ $92.25 \times 1.016 \mathrm{~mm}$ ceramic wafer. Using this platform, the design was expanded to a $16 \times 16$ matrix of 256 chip inductors per wafer. Additional design features included in the wafer were precision machined slots on three sides that provided accurate mechanical registration for screen printing, copper plating, testing, and dicing of the wafer. FIGURE 4 shows the topside winding and bottomside metalization of a wafer used for process development activities.

After the mechanical registration is established, precision machined thru holes ( 2 per device) are laser drilled in the wafer. Initially, the bottomside copper plating pads, copper-filled thru holes, and the series/parallel plating paths for back to front side connectors to each device are completed. Topside conductive layers, vias, and interlayer insulation are added using step-and-repeat screen print and copper plating processes. Each row in the winding matrix is connected in series by the plated thru holes and the rows are in parallel with the plating pads to the electrical current source of the plating equipment. This layout was selected to minimize voltage drops and subsequent plating variations that might adversely affect conductor cross section and effective turn length, which in turn would affect the magnetic parameters of the devices. FIGURE 5 illustrates one layer of a typical winding matrix.

The four-turn configuration containing two turns per layer was selected to optimize conductor cross-sec- 


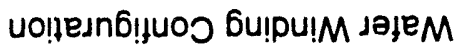

s $\exists \forall \cap$ UIJ

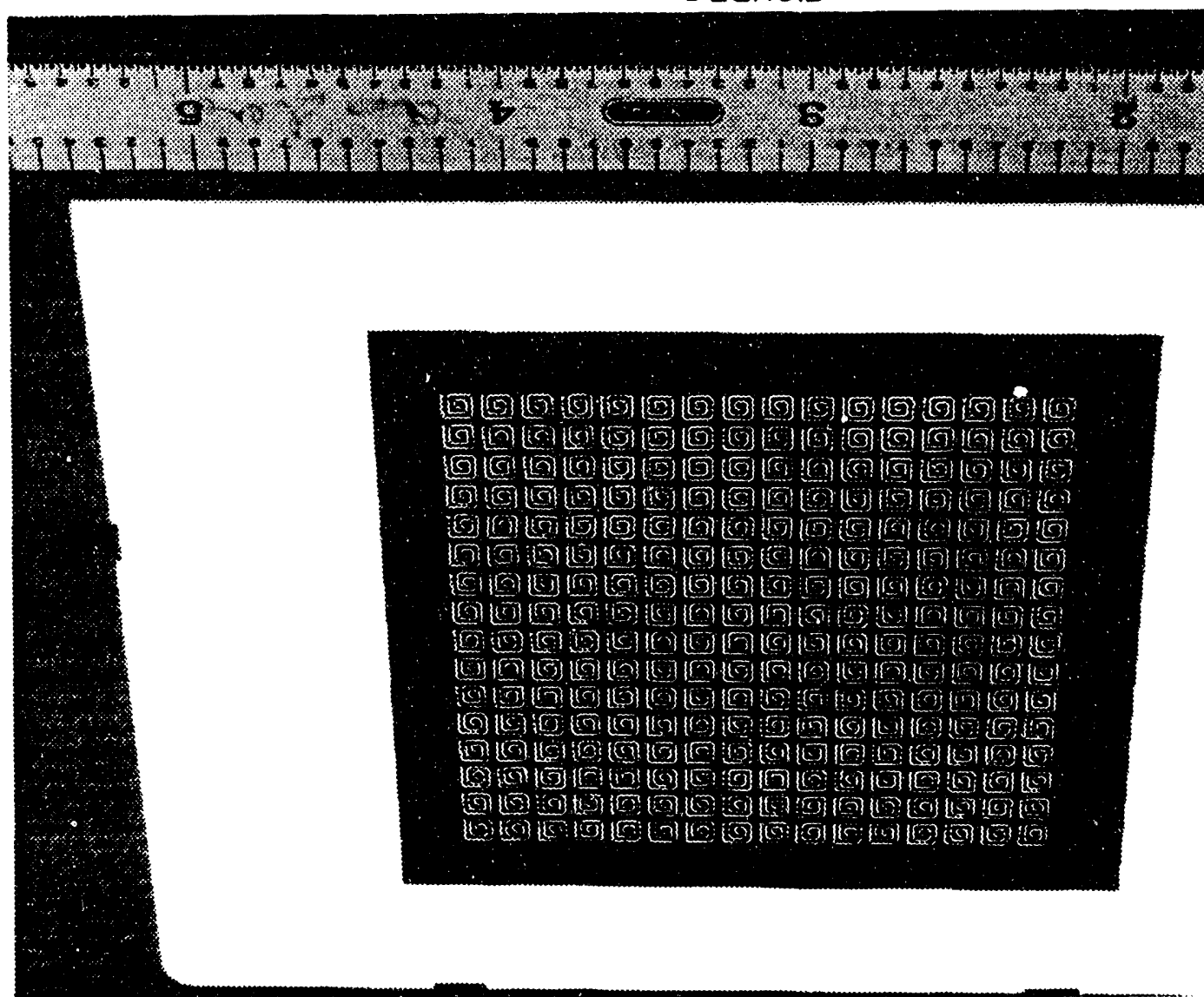

ınoкеา נөןем ә6леา

• 3 女ก

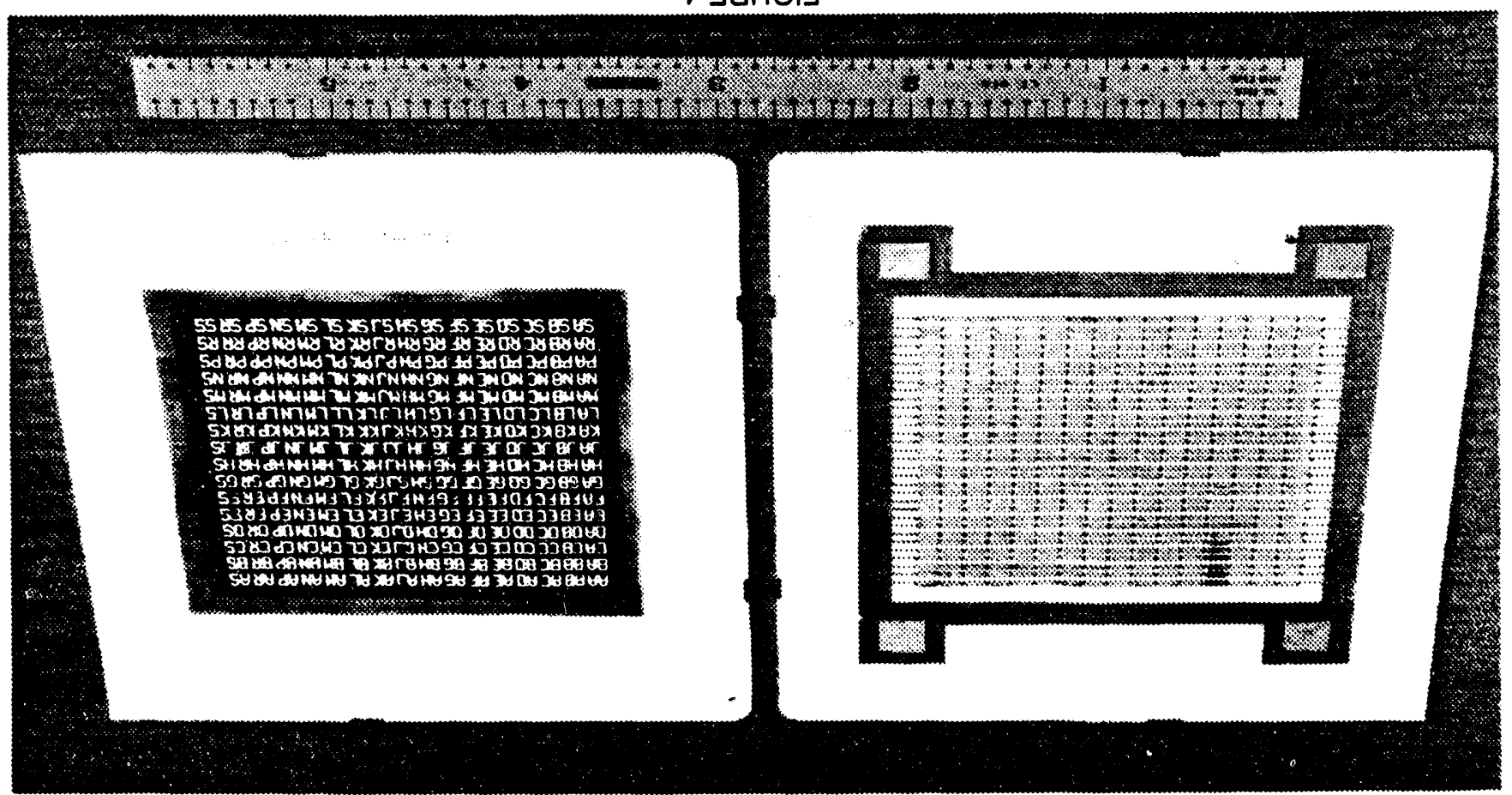


tion versus insulation thickness. Three wafers were fabricated with the various combinations of conductors and insulation. The results are listed in TABLE 3.

FOUR TUAN PROCESS DEVELOPHENT WAFER

\begin{tabular}{|c|c|c|c|c|c|}
\hline $\begin{array}{c}\text { CONDUCTORDELEC } \\
\text { SIZE }(\mu \mathrm{m})\end{array}$ & FREO (MHz) & $L(n H)$ & Cok $5 \%$ & 0 & SRF $(0 \mathrm{OH} 2)$ \\
\hline $254 \times 25.430$ & $\begin{array}{l}100 \\
150\end{array}$ & $\begin{array}{c}34 \\
35.2\end{array}$ & $\begin{array}{l}1.04 \\
0.9\end{array}$ & $\begin{array}{l}34 \\
43\end{array}$ & 0.56 \\
\hline $254 \times 37.5 / 45$ & $\begin{array}{l}100 \\
150\end{array}$ & $\begin{array}{r}33 \\
34.1\end{array}$ & $\begin{array}{l}0.53 \\
0.4\end{array}$ & $\begin{array}{l}41 \\
58\end{array}$ & 0.62 \\
\hline $254 \times 50.8130$ & $\begin{array}{l}100 \\
150\end{array}$ & $\begin{array}{r}30 \\
31.3 \\
\end{array}$ & $\begin{array}{l}0.77 \\
0.7\end{array}$ & $\begin{array}{l}41 \\
55\end{array}$ & 0.52 \\
\hline
\end{tabular}

TWO TURN PROCESS DEVELOPNENT WAFER

\begin{tabular}{|c|c|c|c|c|c|}
\hline $\begin{array}{c}\text { CONOUCTOROEELEC } \\
\text { SIZE }(\mu \mathrm{m})\end{array}$ & FREO (MHz) & $L(\mathrm{nH})$ & Cok $5 \%$ & 0 & SRF (OH2) \\
\hline \multirow{2}{*}{$254 \times 37.5 / 30$} & 100 & 10.3 & 0.65 & $>60$ & $>1.0$ \\
& 150 & 10.3 & 0.64 & $>60$ & \\
\hline
\end{tabular}

TABLE 3

Characteristics of Process Development Wafers

After evaluating the test data and the processing complexities of each, the $37.5 / 30 \mu \mathrm{m}$ conductor/insulator ratio was selected for further evaluation. An additional two-turn wafer was fabricated using the $37.5 / 30 \mu \mathrm{m}$ combination with the results also shown in TABLE 3. This combination was used for the balance of the process development evaluation. In addition to improving $Q$ and SRF, the yields for wafers ranged from $100 \%$ on the two-turn device to an average of $95 \%$ for the four-turn devices. Cpk values for inductance range from 0.53 to 1.04. The large variation was attributed to the visual alignment process used for screen print setup.

The next step in the process characterization of the wafer fabrication was to improve the Cpk of the inductance. The wafer inductance profile, as shown in FIGURE 6, for the two-turn (10nH) coil was typical for all wafers from $10-120 \mathrm{nH}$ (2-10 turns).

There were some differences in the corner values that tended to skew the profile, but the typical upside-down "umbrella" shape of inductance had a spread of $10 \%$ and a calculated Cpk value from 0.9 to 1.1 . The process was repetitive but needed improvement. Cross-sections of individual coils within a wafer showed slight variations in conductor thickness and location from the outer edge to the center. These minor changes contributed to the "umbrella" effect. The screen prints used to gener-
WAFER INDUCTANCE PROFILE

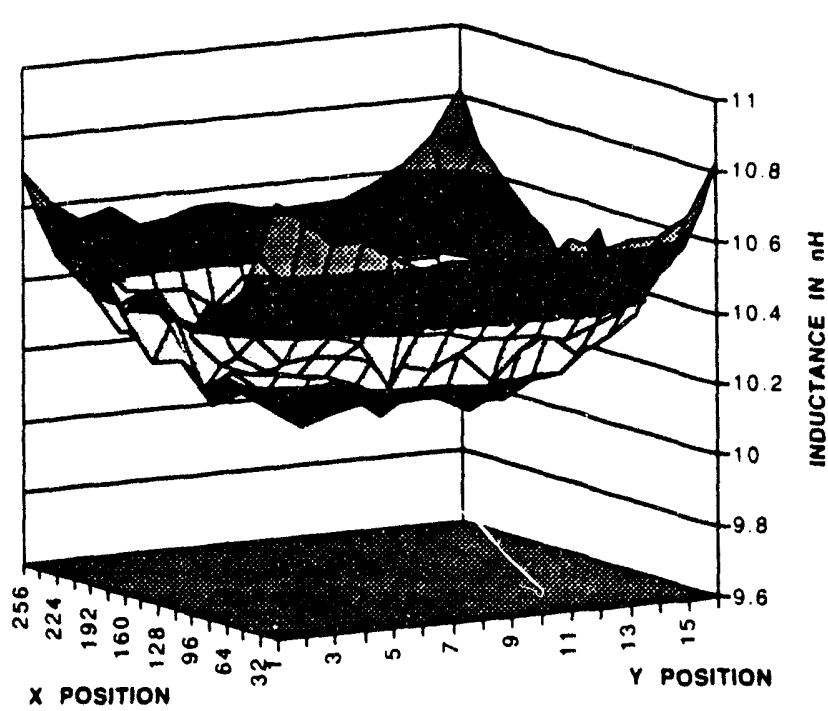

FIGURE 6

ate each layer, as previously shown in FIGURES 4 and 5 , consisted of a series of 16 rows with 16 devices connected in series and then joined at the top and bottom by parallel connections to the four corner pads. By breaking up this large matrix into smaller cells, the potential voltage drop within any one row during the plating process could be reduced, thus minimizing the effect location within a wafer would have on conductor width, thickness, effective turn length, and inductance. To assess the impact this change would have on the inductance profile, the screens were redesigned into 16 cells, each containing 16 devices. FIGURE 7 shows a

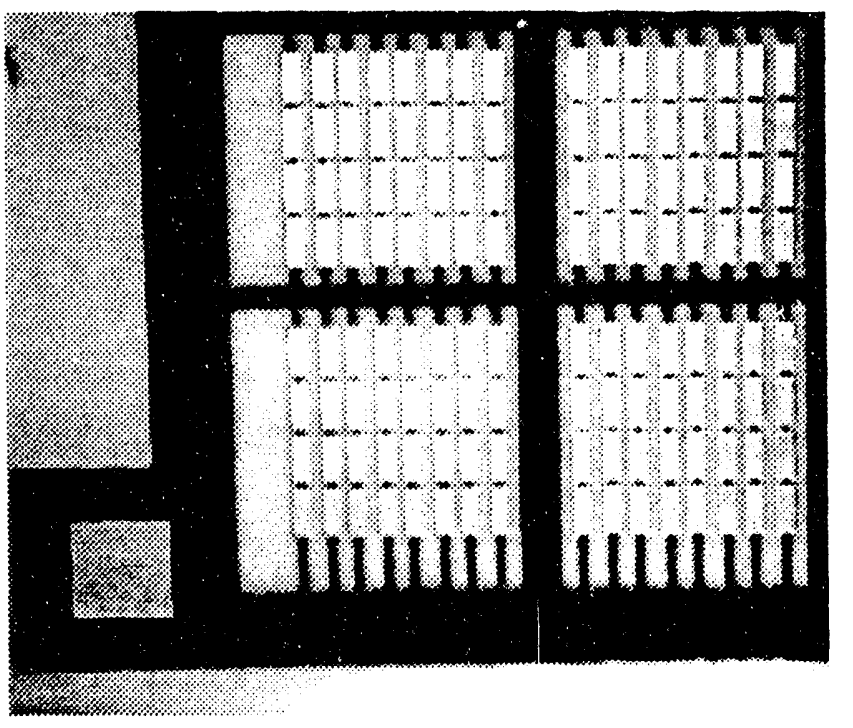

FIGURE 7

Example Portion of 16-Cell Lavout 
portion of the new wafer layout.

$T^{\prime}$ maximum series path is only 4 devices long. A prorile with 16 discrete "umbrellas" was expected. However, the results showed that the inductance profile had the same basic "umbrella" shape with some minor scalloping along the edges. Statistical analysis of a 16 cell inductance profile showed some improvement. The maximum spread of inductance

WAFER INDUCTANCE PROfile .- 16 CELL LAYOUT

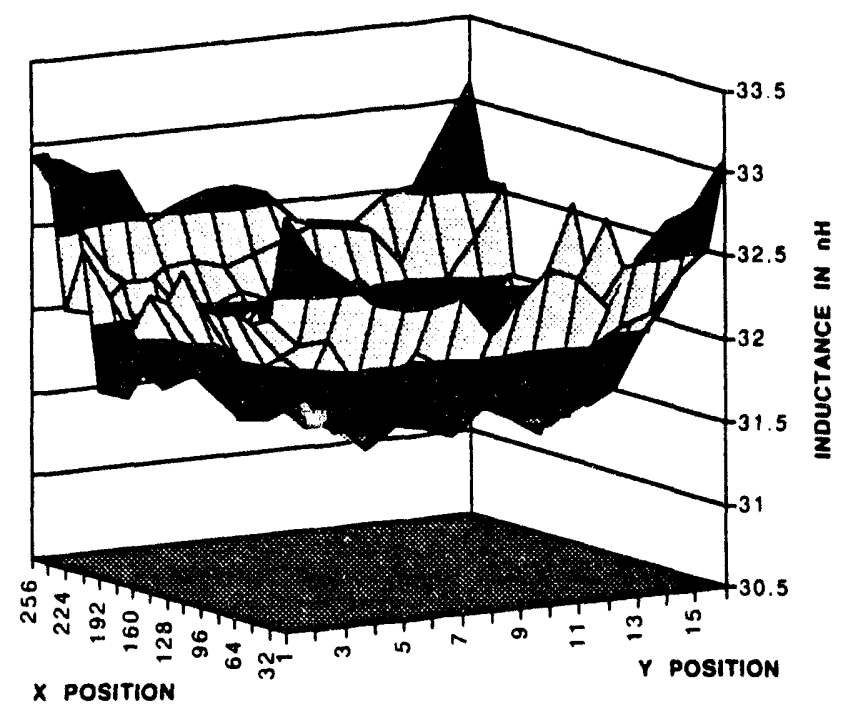

FIGURE 8 values across the wafer (FIGURE 8) went from approximately $10 \%$ to $5.4 \%$, and the Cpk of the wafer went from approximately 1.0 to 1.40. There was improvement, but the results were still short of the goal of a Cpk of 1.67 minimum. The basic shape of the wafer inductance profile remained unchanged, so the root cause of the "umbrella" effect had not been identified.

$Q$ vs. frequency and SRF data for the 10,36 and 75 $\mathrm{nH}$ devices are illustrated in FIGURE 9. The $\mathrm{Q}$ factors for these values are equivalent to wire wound devices, but SRF values for the 36 and $75 \mathrm{nH}$ parts are slightly less than specification requirements.

Further analysis of the wafer structure suggested that thermal stress induced during the screen-print and plating processes was warping the wafer because of large differences in the COTE between the ceramic wafer, copper winding and the polyimide insulation. To evaluate the thermal stress factor, three 6-turn wafers having thicknesses of 1.016 , 1.27 and $1.524 \mathrm{~mm}$ were fabricated. Because the -mechanical stiffness of the wafer increases by the cube of its thickness $(t)^{3}$, it was hoped that wafer thickness was the final piece to corrplete the puzzle. Preliminary data on the three wafers indicates a slightly greater than $1 \%$ improvement on the inductance spread. Additional analysis will be required at other inductance values to determine if the thickness

Q factor versus faequency

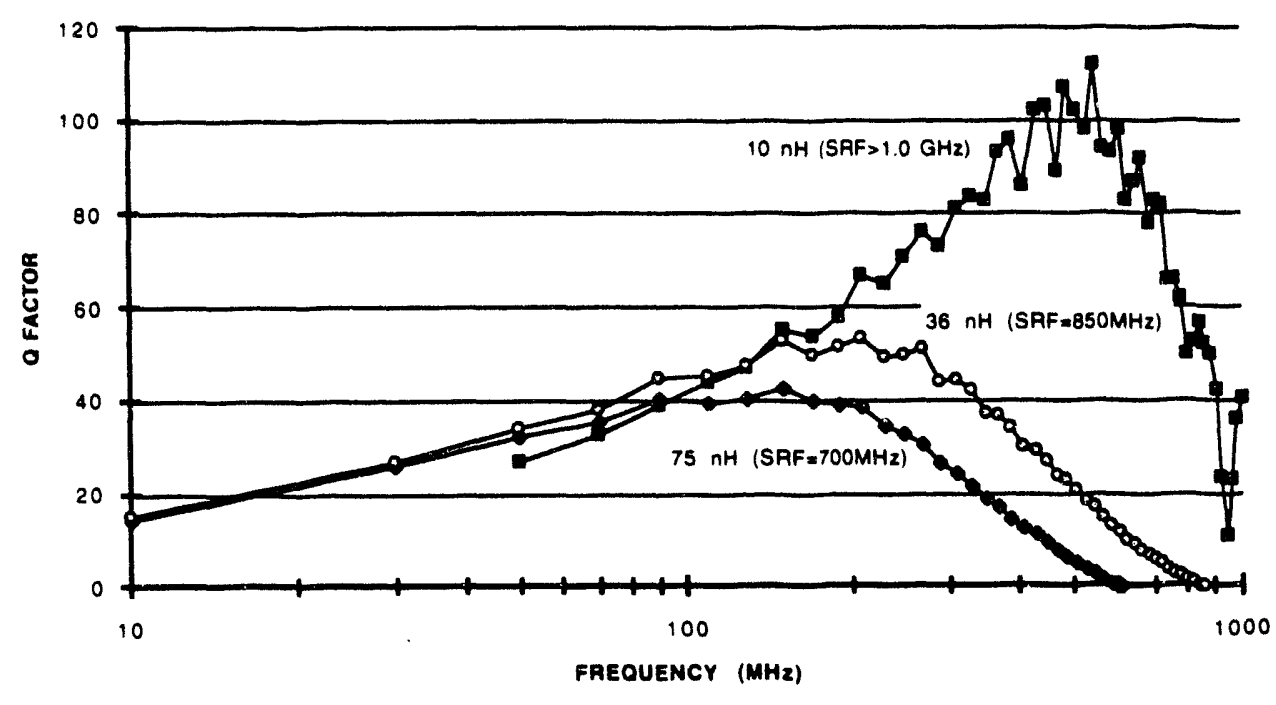

FIGURE 9 
factor improvement is real and can be achieved across the range of inductors or if process limits have been reached.

\section{Test Equipment Development}

In order that the design concept of waferized planar chip inductors be a viable production process, it was necessary to develop an automated method for the RF in-process and final testing of wafers. An industry search revealed that semi-automated probe stations were available but not really suited to the production environment. Borrowing from an ElectroFix, Inc. patented Pad Finder ${ }^{\circledR}$ probe station previously developed for AlliedSignal Kansas City Division (ASKCD) for continuity and multi-point electrical isolation testing of multilayer TKNs, a contract for the development of an automated RF probe station was placed with Electro-Fix. This action evolved into a PC driven automated probe station capable of testing and performing statistical analysis on RF electrical measurements at the rate of $\mathbf{4 5}$ parts per minute. Test speed is limited primarily by the HPIB response time to the computer commands.

Accurate calibration of the HP4191A Impedance Analyzer was an essential element in the development of the probe station. Normally, the HP4191A is calibrated at the $7 \mathrm{~mm}$ port with an open, short and $50 \mathrm{ohm}$ load. When test fixtures are added to the RF port, a correction factor, the electrical length of the test fixture, is added to the instrument to compensate for the offset. The correction factor normally is less than $1 \mathrm{~cm}$. For the RF probe station to accurately test planar chip inductor wafers mounted on the $\mathrm{Pad}$ Finder ${ }^{\circledR}$ test bed, it was necessary to add a $70 \mathrm{~cm}$ Sucoflex flexible microwave cable assembly to the HP4191A Impedance Analyzer. The HP4191A could not compensate for such a large offset. The most accurate approach would be to have a set of calibration standards built into each production wafer. This was impractical, so a calibration wafer standard was fabricated containing 3 sets of opens, shorts, and $50 \mathrm{ohm}$ TFN loads on the same ceramic platform used for wafer fabrication. This permitted calibration of the HP4191A at the point of test.

Correlation and repeatability tests of wafers and discrete chips were performed, both on the RF probe station and in the ASKCD Metrology Department. Excellent correlation between the Metrology tests and the automated RF probe station were obtained. The one remaining area of concern involves $Q$ mea. surements above $700 \mathrm{mHz}$. The calibration standards fabricated for the RF probe station were noncoplanar. ASKCD Metrology ran a series of tests comparing their coplanar wafer $50 \mathrm{ohm}$ standards to the non-coplanar standards fabricated for the RF probe station. As seen in FIGURE 10, the accuracy of the non-coplanar standard starts to roll off at 700 $\mathrm{MHz}$.

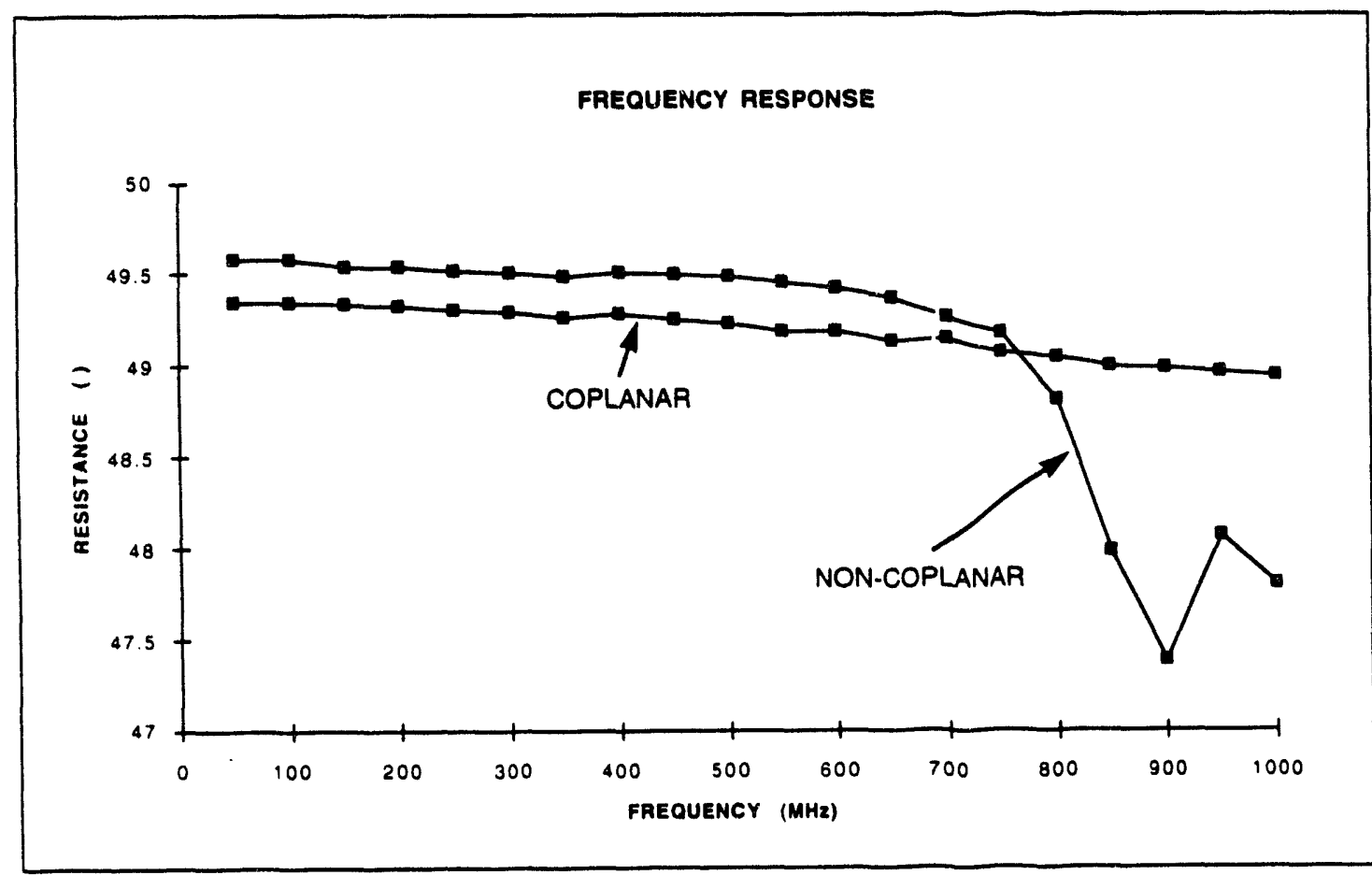

FIGURE 10

Frequency Response -- $50 \Omega$ Thin Film Calibration Standards 
Because of HP4191A instrumentation uncertainties at $Q$ factors above 60 and the errors in $Q$ introduced by the non-coplanar calibration standard $50 \mathrm{ohm}$ load above $700 \mathrm{mHz}$, the $Q$ values above $700 \mathrm{mHz}$ in Figure 9 will have to be reevaluated when a new coplanar wafer calibration standard, now being fabricated, is tested and certified by Metrology.

\section{Summary}

The goal of the project was to develop a family of planar chip inductors $(5-100 \mathrm{nH})$ thai are equivalent to the MIL-SPEC-M83446/8 devices cLirrently used on DOE weapons programs. Most of this key elements of the project have been accomplished. Some additional work is planned for 1995 and must be completed before planar chip inductors utilizirig plated multilayer copper conductors are a viable low cost option for high reliability RF signal and power applications. Future activities include completion of system qualification tests and the evaluation of planar devices installed in RF assemblies. In addition, process characterization activities are planned to further improve Cpk of inductance, and to increase SRF.

Perhaps the most significant achievements of this project to date were the development of the coplanar waferized calibration standards and of the auto.mated RF probe station. This integrated test platform was designed for high speed RF testing, statistical analysis, and sorting of chip inductor wafers. With minor modifications, it could easily be adapted for discrete component testing.

\section{References}

[1] United States Department of Energy Contract Number DE-AC04-76-DPO0613.

[2] H. Dicken, "Semiconductor Reliability News," Vol. VI, Number 3, March, 1994, DM Data, Inc.

[3] R. Brown, "Materials and Processes for Microwave Hybrids," 1991, ISBN 0-930815-31-9.

[4] A. Balakrishnan, W. Devereux Palmer, W. T. Joines, T. G. Wilson, "The Inductance of Planar Structures," 1993, IEEE 0-7803-0982 pg. 914, 915. 

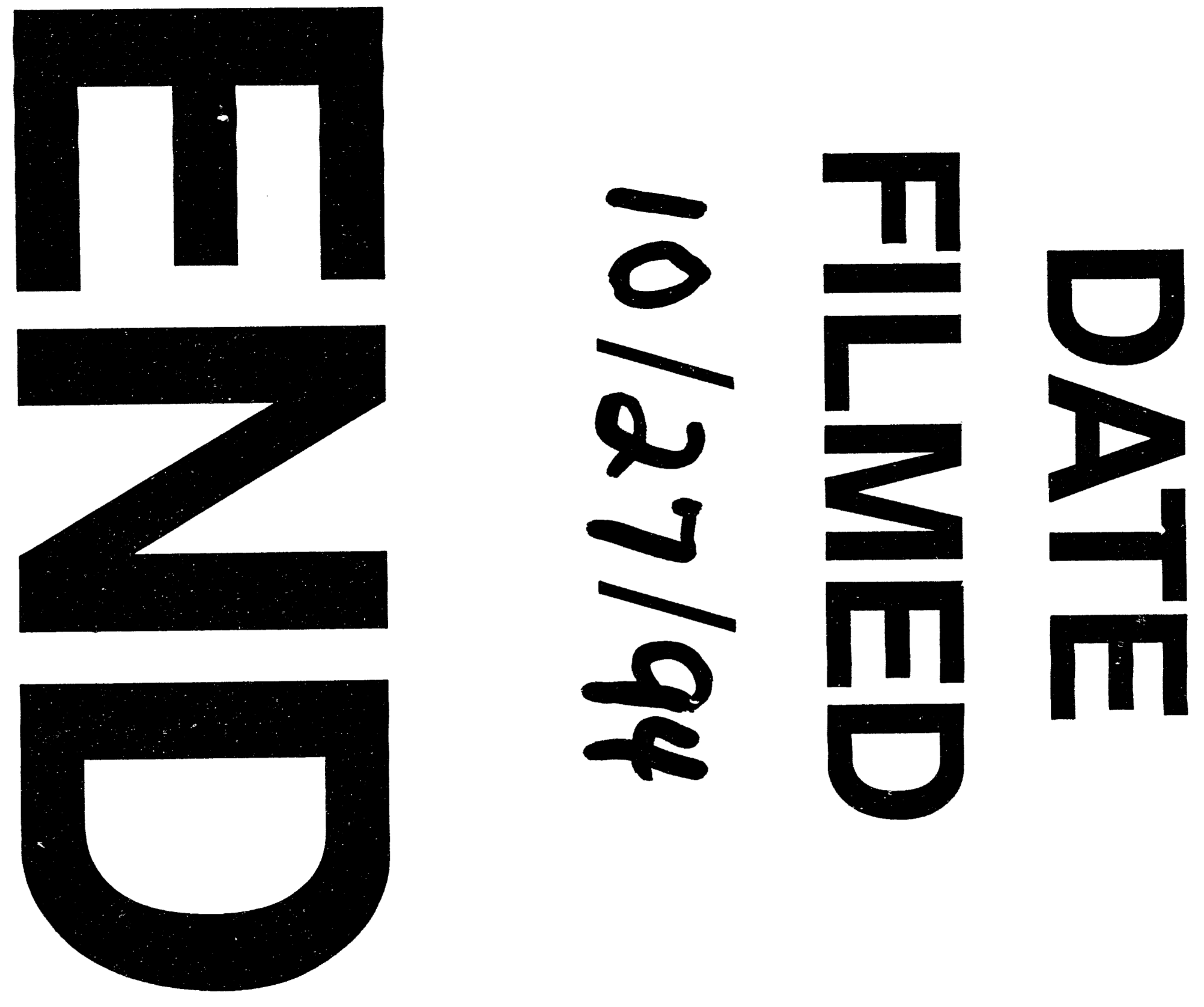